\title{
Morbid obesity and its comorbidities
}

\begin{abstract}
Background: People who suffer from morbid obesity (MO) are at high risk for many diseases, atherogenic dyslipidemia, elevated blood pressure, type 2 diabetes, thromboembolism, hepatic steatosis, proinflammatory state, etc. Metabolic syndrome is characterized by the clustering of some, or all, of these metabolic abnormalities in the presence of underlying insulin resistance with a strong association with diabetes and cardiovascular disease morbidity and mortality. The pathophysiology is attributable to insulin resistance. Increased release of free fatty acids (FFAs) from adipocytes blocks the insulin signal transduction pathway, which induces endothelial dysfunction due to the generation of increased reactive oxygen species (ROS) and oxidative stress. Dyslipidemia, associated with high levels of triglycerides and low concentrations of high-density lipoproteins (HDLs), contributes to a proinflammatory state. These risk factors are strongly associated with an excess of, and a particular bodily distribution, of adipose tissue.
\end{abstract}

Going deeply into the biochemical and molecular knowledge of co-morbidly associated to the morbid obesity and the changes that it experience with the bariatric surgery: alterations of lipid metabolism, hepatic steatosis, satiety factors, thrombophilia or stress.

The Roux-en-Y gastric bypass (RYGBP) has become the gold standard of bariatric surgery. It represents a mixed technique, combining restriction derived from leaving a small stomach pouch near the esophagogastric junction by excluding the greater curvature, together with a small malabsorptive component derived from bypassing most of the stomach and duodenum. Surgical weight loss approaches are based on intestinal malabsorption and gastric reduction. "Success" has been defined as a maintained weight loss of $\geq 50 \%$ of excess body weight, which in turn is defined as the difference between body weight and ideal weight (for a given patient's gender and height).

Keywords: morbid obesity, thromboembolism, hepatic steatosis, oxygen species, tissue, body weight, ethiopathogenic
Volume 6 Issue 2 - 2018

\author{
Eva Pardina,' Julia Peinado Onsurbe,' Júlia \\ Carmona,' 'David Ricart Jané,' Antonio \\ Miñarro, ${ }^{2}$ Roser Ferrer, ${ }^{3}$ Albert Lecube, ${ }^{4}$ \\ Elena Cuello, ${ }^{5}$ Juan A Baena Fustegueras ${ }^{5}$ \\ 'Department of Biochemistry and Molecular Biomedicine, \\ Barcelona University, Spain \\ 2Department of Genetics, Microbiology and Statistics, Biology \\ Faculty, Barcelona University, Spain \\ ${ }^{3}$ Department of Biochemistry, Institut de Recerca Hospital \\ Universitari Vall d'Hebron, Barcelona University, Spain \\ ${ }^{4}$ Department of Endocrinology and Nutrition, Arnau de Vilanova \\ University Hospital, CIBER de Diabetes y Enfermedades \\ Metabólicas (CIBERDEM, Spain \\ ${ }^{5}$ Endocrinology Surgery Unit, Arnau de Vilanova University \\ Hospital (UdL), Lleida, Spain
}

\author{
Correspondence: Julia Peinado Onsurbe, Department of \\ Bioquímica y Biología Molecular Facultat de Biologia, Universitat \\ de Barcelona, Diagonal 643, 08028 Barcelona, Spain, Tel (34)- \\ (3)-402I524/48, Fax (34)-(3)-402I559, \\ Email:jpeinado@ub.edu
}

Received: October 26, 2017 | Published: April 13, 2018
Abbreviations: BMI, body mass index; FFA, free fatty acid; HDL, high density lipoprotein; HL, hepatic lipase; HSL, hormone sensitive lipase; LDL, low density lipoprotein; LPL, lipoporotein lipase; NEFA, non-esterified fatty acids; PL, phospholipids; PPAR, peroxisome proliferator-activated receptors; QM, chylomicron; ROS, reactive oxygen species; RYGBP, Roux-en-Y gastric bypass; SAT, subcutaneous adipose tissue; TAG, triacylglycerides; TC, total cholesterol; TZD, thiazolidinediones; VAT, visceral adipose tissue; VLDL, very low density lipoprotein.

\section{Morbid obesity}

Obesity is defined as the abnormal storage of fat reserves, and it is a disease that limits activity, shortens lifespan and is highly prevalent in developed societies such as the West. Despite the epidemic spread of this disease, there is currently no fully effective system for its treatment. ${ }^{1}$ It is estimated that the economic cost of obesity in developed countries is $2-7 \%$ of the cost of healthcare, which represents a very significant monetary expenditure devoted to healthcare in a country. ${ }^{2}$

Morbid obesity is defined as a body mass index (BMI) $\geq 40 \mathrm{~kg} /$ $\mathrm{m} 2$ or a BMI under 40 in the presence of significant comorbidities. Although not many studies have been published on the prevalence of morbid obesity in populations, recent data indicate that in 2010, 15.5 million adult Americans or $6.6 \%$ of the population had an BMI $\geq 40 \mathrm{~kg} / \mathrm{m} 2$. The prevalence of clinically severe obesity continues to be increasing, although less rapidly in more recent years than prior to $2005,{ }^{3}$ which is significantly higher than that estimated for Spain ( $4 \%$ of obese people). ${ }^{4}$ In general, the prevalence of morbid obesity is $2-3$ times higher in women, tends to increase with age, especially in women, and affects less privileged socio-economic and cultural groups.5

Morbid obesity is associated with significant comorbidities (endocrine- metabolic, respiratory, digestive, vascular, cardiac and psychosocial diseases, as well as high risks of some cancers). Currently, it is believed that the development of diseases associated with obesity is not as important as the amount of fat deposited and the area of the body where it is located. The accumulation of intraabdominal visceral fat in the mesentery and omentum is considered to be a better predictor of coronary heart disease that the body mass index. The pathophysiology of subjects with intra-abdominal visceral fat accumulation is closely related to the so-called metabolic syndrome $\mathrm{X}^{6}{ }^{6}$ While central obesity is frequently associated with psychosocial and socio- economic difficulties, excessive use of cigarettes and alcohol and emotional conditions, such as anxiety and depression, peripheral obesity lacks these associations, suggesting that there is even a negative relationship between them. ${ }^{7}$

There is no doubt that a primary risk factor in cardiovascular disease is hypertriglyceridemia, which is considered to be a risk factor for obesity, diabetes, stress, etc. It should be noted that morbid obesity is usually accompanied by diabetes and/or hyperlipemia. ${ }^{8}$ 
Of the strategies used for the treatment of obesity, including limitation of food intake, increased energy expenditure and bariatric surgery, the last has been shown to be the most effective method to improve morbid obesity. ${ }^{1}$ In addition to patients whose obesity is associated with a BMI $\geq 40$, patients with a lower BMI and osteoarthritis, diabetes, hypertension, infertility, psychosocial problems, etc. are also candidates for surgery. Some surgical techniques that induce malabsorption or reduce gastric volume have been developed for the treatment of patients who fail to lose weight steadily. The first type of treatment requires a survey of protein malnutrition and other conditions, the latter involving a reservoir and a small stoma, and in both cases it is necessary to monitor these conditions long term. Between 15 and $40 \%$ of patients, depending on the procedure, fail to maintain a steady decrease in weight. However, the successful reduction that is achieved in most cases justifies this type of surgery, which improves such a devastating disease and achieves a clear improvement in quality of life. ${ }^{9}$

\section{Using animal models to study obesity and/or diabetes}

Because one of the major risk factors for obesity is hypertriglyceridemia, experimentally obese and/or diabetic animals have been used to study the mechanisms by which hypolipidemic drugs produce their effects. These effects have been studied both in plasma and different tissues (adipose, heart, liver, etc.) by determining lipid profiles, lipolytic activity of lipoprotein lipase (LPL) and hepatic lipase (HL), the expression of different apoproteins and the molecular mechanisms (transcription factors such as PPAR $-\alpha, \beta$ and $\gamma$ ) through which different genes are regulated.

The effects of antidiabetics, such as thiazolidinediones (TZD), have been studied in obese diabetic rats, and rexinoids (derivatives of vitamin A that are used to treat certain skin diseases and cancer) have been studied in normal and diabetic rats. In the diabetic rats, it was observed that high hypertriglyceridemia was produced by a drastic decrease in LPL. ${ }^{10}$ Modified fatty acids (FA) that activate the transcription factor PPAR $-\alpha$ decreased the liver expression of genes involved in lipid metabolism, such as apoClll, ApoAl or apoAlV, while PPAR- $\gamma$, which regulates the LPL gene in white adipose tissue WAT, did not produce changes in the activity or in the enzyme mRNA level. ${ }^{11}$ Ligands of PPAR $-\gamma$ in obese mice decreased LPL activity in WAT. ${ }^{12}$ Oleoyl-estrone in obese Zucker rats has been shown to produce a reduction in body weight..$^{13,14}$ Both in obese and in normal rats, not only the lipoprotein profile ${ }^{15,16}$ but also analysis of cholesterol transport $^{17}$ indicated a reduction of LPL activity in WAT and HL activity in the liver, as well as a lipid-lowering effect in plasma ${ }^{18}$ On the other hand, the effects of fibrates and other lipid-lowering drugs have been studied in mice and rats in vivo and in vitro, and a reduction in hypertriglyceridemia caused by obesity and/or diabetes was observed ${ }^{19,20}$

\section{Adipose tissue}

Adipose tissue mass in mammals is maintained by a dynamic equilibrium between lipid storage, which is mediated by lipoprotein lipase (LPL), and fat mobilization (lipolysis), which is regulated by hormone-sensitive lipase (HSL). Both enzymes play important roles in obesity ${ }^{8}$ However, there is still uncertainty about the importance of each enzyme in the acquisition and maintenance of fat deposits, particularly in subcutaneous (SAT) and visceral (VAT) adipose tissue in morbidly obese patients.
LPL is the enzyme responsible for hydrolysis of circulating TAG from QM and VLDL. ${ }^{21,22}$ The enzyme functions as a dimer and is located in the light of capillaries, anchored to endothelial cells by heparin and dermatan sulfate moieties. ${ }^{23}$ After a short half-life, the enzyme monomerizes, losing its activity, and is released from its anchor to travel freely through the blood (possibly bound to LDL ${ }^{24}$ ), which is then taken up mostly by the liver, internalized and degraded. Sometimes, some LPL molecules are released in the dimeric form (active), which causes LPL activity to appear in the blood and liver ${ }^{25}$ The presence of activity in the tissue determines its capacity to use fatty acids that are part of the TAG of lipoproteins. The enzyme is expressed and located at high levels in white and brown adipose tissue, heart, muscle and lactating mammary gland. ${ }^{26}$ Changes in LPL activity are important, first because it changes the flow of TAG between different tissues and second because it generates low-density lipoprotein (LDL), a clear atherogenic characteristic. ${ }^{27}$

The importance of LPL in WAT and its role in the regulation of the origin and/or maintenance of obesity are not yet fully understood. However, experiments in rats and humans have led to the suggestion that the role of the enzyme is to preserve the constancy of adipocyte volume ${ }^{28}$ With some exceptions, ${ }^{29}$ in LPL studies in obese humans, the enzyme was released from WAT with heparin, and an increase in LPL activity was shown by the cells. ${ }^{28}$ However, when the data are expressed per gram of tissue, the activity has been described to increase, ${ }^{30}$ decrease ${ }^{31}$ or remain unchanged compared to lean controls. ${ }^{32}$ Expressing LPL activity per gram of tissue can be misleading because it does not take into account whether the number and/or volume of cells increases, decreases or remains unchanged. When a study was conducted in obese individuals undergoing weight reduction by dietary changes, the results unanimously indicated that there was an increase in the LPL mRNA and activity in WAT ${ }^{33}$ however, there were also discrepancies, and not all the authors observe changes in the expression of the enzyme. ${ }^{34}$ However, practically no studies have been carried out on LPL in patients undergoing bariatric surgery.

One way to avoid possible mistakes is to express LPL activity by DNA quantity, which results in increased LPL activity in parallel with obesity, reaching a peak in morbid obesity; on the other hand, despite the increased LPL in WAT, parallel increases in plasma TAG and cholesterol from VLDL were also observed. ${ }^{35}$

\section{LPL activity}

According to Marin and coworkers, ${ }^{36}$ there are differences in the TAG uptake capacity between different adipose deposits. The uptake of labeled TAG is approximately $50 \%$ higher in omental adipose tissue than in subcutaneous abdominal adipose tissue in men with a wide range of body fat. However, these results did not correlate with LPL activity. ${ }^{36}$ The increase in visceral fat mass with increasing total body fat could be explained by an increase in fat cell size, but only up to a certain adipocyte weight. Further increases in intra-abdominal fat mass with severe obesity appear to be due to higher numbers of adipocytes. ${ }^{37}$ Considering that visceral adipocytes compete with other adipose tissues, in addition to muscle, for circulating TAG from VLDL and QM, it is reasonable to expect that determining the LPL activity in different adipose tissues and factors that regulate or modify this activity could help to prevent and/or correct visceral adiposity.

\section{HSL activity}

The data on obese human HSL activity are also controversial, 
mainly because of methodological differences among the available studies. ${ }^{38}$ Some authors demonstrated that the expression and function of HSL in subcutaneous adipocytes are defective in obese patients. These HSL defects were accompanied by decreased lipolytic capacity of adipocytes when lipolysis was expressed per gram of lipid in fat cells. Lipolysis per gram of lipid is a better measure of lipolytic capacity than lipolysis per cell, as fat cell volume increases in obesity. Moreover, there is a relationship between cell size and the lipolysis rate per cell but not per gram of lipid. ${ }^{39}$ We have also recently described $^{40}$ HSL activity in the morbidly obese. Similarly to LPL, HSL values observed in SAT and VAT from obese or control subjects were approximately the same. If we compare these two groups, obese individuals had 2.8 times more activity per gram of tissue than controls ( $<<0.001 \mathrm{vs}$. control) in both SAT and VAT, despite having fewer cells per gram of tissue. Moreover, they also have more HSL activity per cell than controls $(p<0.001)$, which increases fatty acid delivery to plasma by two-fold). This higher lipolytic capacity was also reflected when data were expressed as HSL activity per BW. In both SAT and VAT, obese subjects displayed five times more activity than controls $(\mathrm{p}<0.001){ }^{40}$

There are also conflicting data about LPL and HSL activity after weight loss. ${ }^{41}$ Some authors observed that, when obese subjects lost weight and became less hyperinsulinemic, adipose LPL continued to increase. This suggests that abnormal LPL regulation is independent of insulin..$^{38}$ Others reported that weight loss did not change the lipolytic capacity of adipocytes or their capacity for storing TAG. ${ }^{42,43}$ These inconsistencies may be related to a) the way the enzyme activities were expressed (tissue weight, protein, DNA, etc.) and b) the difficulties in measuring LPL activity, since a portion of the enzyme remains inaccessible in the tissue extracts. In contrast, measures of HSL activity give the total amount of enzyme in the tissue ${ }^{42}$ Recently, in morbidly obese patients submitted to weight loss with bariatric surgery, we have observed that the LPL activity profile in SAT was similar independently of the units used to express it; moreover, this activity decreased one year after surgery to the LPL values observed in patients with normal weight. This decrease affects the amount of TAG stored in the tissue, which during this time is also decreased. ${ }^{41}$ After bariatric surgery, HSL activity per gram of tissue in SAT showed a linear increase until 12 months $(\mathrm{r}=0.98, \mathrm{p}<0.001)$. Thus, lipolytic capacity of obese patients seemed to increase after surgery $(p<0.001$, 6 months and 12 months vs. obese. Nevertheless, we must take into account that the cells are progressively smaller; thus, HSL activity per cell remained steady. Total HSL activity was also stable during the follow-up period, which was in agreement with the elevated concentrations of NEFA observed in plasma. ${ }^{41}$

\section{Plasma}

Studies carried out in human postheparin plasma from obese individuals generally show that HL is more important than LPL. HL is an enzyme synthesized in the liver, and its primary function is the hydrolysis of TAG from TAG-rich HDL2, which is converted into HDL3. It also has the capacity to hydrolyze phospholipids from the surfaces of lipoproteins. This enzyme, like LPL, exerts its function in the lining of capillaries and, also like LPL, can be released by heparin administration, since it is anchored on endothelial cells by specific glycosaminoglycan chains. The enzyme is synthesized in hepatocytes, but, after synthesis, it is immediately released to the endothelium, unlike LPL, which is intracellularly processed in a highly regulated and complex process. The HL enzyme has an important role in reverse cholesterol transport and capture of QM remnants. On the other hand, it is also present in steroidogenic organs where it travels, through the blood, from where it was synthesized to the liver. ${ }^{44}$

HL has been reported to increase in postheparin plasma from obese individuals and to be positively correlated with visceral fat deposition, and a decrease in enzyme activity has also been reported, which possibly results in low levels of HDL2 cholesterol. After weight reduction in obese individuals, there was a decrease in postheparin plasma HL activity with increases in HDL cholesterol and esterified cholesterol ${ }^{45}$ This last observation is very interesting because the risk of cardiovascular disease also decreases with body weight. We made the same observation recently in preheparin plasma. ${ }^{46}$ There is little information in the literature about lipolytic activity in the plasma of human obese or morbidly obese individuals at baseline, i.e., not in plasma postheparin. In basal conditions, the real lipolytic capacity of plasma can be determined, while after injection of heparin, the activity measured in plasma corresponds to total body LPL released from different tissues (white adipose, brown adipose, muscle, heart, diaphragm, lung, etc.). Although it is true that a large proportion, under normal conditions, corresponds to white adipose tissue, at a more or less severe hypertriglyceridemia, such as obesity with or without diabetes, the situation may be very different. Furthermore, determination of the mass of the LPL enzyme, similarly to HL, can indicate whether a case of hypertriglyceridemia, caused by LPL, is due to a deficiency in the synthesis of the enzyme, a deficiency in functionality and/or the existence of inhibitors of the enzyme in plasma, ${ }^{47}$ i.e., apoClll and/or deficiency in the plasma enzyme activity of apoCll. The determination of HL in the plasma and liver gives information about reverse cholesterol transport and the direct relationship between HL activity and levels of cholesterol and plasma phospholipids. It is noteworthy that the increases in FA and free cholesterol can lead to changes in the fluidity and plasticity of the plasma membranes of cells where LPL and HL are anchored.

Similar discrepancies concerning the effect of reducing body weight to those observed in tissues have also been described for plasma LPL and HL lipases, which are always measured in postheparin plasma. So, while there are authors who did not observe the differences in LPL activity before and after weight loss, ${ }^{48}$ other authors observed an increase. ${ }^{49}$ We have seen that both LPL $^{50}$ and $\mathrm{HL}^{46}$ activity in preheparin plasma in the morbidly obese are higher $(0.59 \pm 0.11$ and $4.31 \pm 0.94 \mathrm{mU} / \mathrm{mL}$ plasma, respectively) than in individuals with normal weight $(0.18 \pm 0.07 \mathrm{mU} / \mathrm{mL}$ plasma, $\mathrm{p}<0.01$ and $2.46 \pm 0.17 \mathrm{mU} /$ $\mathrm{mL}$ plasma, $\mathrm{p}<0.05$, respectively). When the individual lost weight, after one year, while the HL recovered to the normal value, the LPL remained virtually unchanged. ${ }^{46,50}$ Changes in HL were accompanied by changes in almost all plasma lipids except NEFA. ${ }^{46}$

\section{Liver steatosis and obesity}

A further complication in $90 \%$ of cases of morbid obesity ${ }^{51}$ for which a plausible explanation has not yet found, is non-alcoholic fatty liver (NAFL) disease, which is not currently diagnosed, as evidence of clinical or biochemical changes and liver biopsy are not used to detect progress (fibrosis, cirrhosis) of the disease. ${ }^{52}$ While there is some evidence to suggest that obesity, diabetes, old age and perhaps an aspartate transaminase/alanine transaminase (AST/ALT) ratio greater than one can predict most advanced liver fibrosis, histology remains the best tool for diagnosis. ${ }^{52-55}$ 
In 1979, the presence of LPL activity in livers of rat fetuses and neonates was first described in experimental animals in different physiological and metabolic situations. ${ }^{56}$ Later, its expression, ${ }^{57}$ its functional tissue localization, ${ }^{58}$ its response to physiological stimuli, ${ }^{59-61}$ the cells involved in synthesis in the liver, ${ }^{62}$ its mechanisms of regulation ${ }^{63,64}$ and the physiological significance of its perinatal presence in the liver were described. ${ }^{65}$ In the liver of adult animals, LPL activity is also present in some physiological or experimental situations, ${ }^{66-68}$ but in most cases, the enzyme travels from other tissues via the blood. The presence of LPL activity and mRNA in adult rat regenerating livers was also described ${ }^{69}$ as well as the identification of at least two types of receptors in the liver involved in the process of collecting the circulating LPL. ${ }^{70}$

It has been suggested that increased visceral fat implies a high flux of fatty acids (FA) and metabolism, which exposes the liver to the FA, causing increased secretion of very low density lipoprotein (VLDL) and promoting metabolic abnormalities, such as glucose intolerance, diabetes, non-dependent and/or dyslipidemia, with a consequent increase in cardiovascular disease. Moreover, the decrease of LPL in muscle and WAT reduces peripheral hydrolysis of TAG, which causes an increase in the return of chylomicrons (QM) and VLDL to the liver, leading to the stimulation of production of these lipoproteins. ${ }^{42}$

Insulin resistance and, therefore, hyperinsulinemia are common features found in patients with and without diabetes mellitus who were or were not obese, ${ }^{71,72}$ and this plays an important role in the generation of damage liver, so that the severity of hepatic failure is proportional to the severity of insulin resistance. Some authors suggest that the presence of diabetes and the time of development are important factors to identify patients with deeper hepatic lesions. ${ }^{73}$

We recently described ${ }^{46,50}$ that liver steatosis causes an accumulation of all kinds of lipids and that a year after bariatric surgery, except for the FA, the levels of all lipids decrease to normal. From the beginning, our hypothesis, from our experience in experimental animals, was that if these lipids were FA and/or TAG, the origin of these lipids may be due to an abnormal presence of LPL in the liver during the development of the disease; this LPL could have an origin in other tissues, such as fat, or the liver itself. But if the accumulated lipids were cholesterol or cholesterol esters, the enzyme involved is probably HL. The first part of the hypothesis is supported by the fact that patients with morbid obesity and possibly steatosis were also hypertriglyceridemic and were given fibrates as a treatment, and an increase in LPL expression and activity in the livers of experimental animals treated with fenofibrates has been shown. ${ }^{19}$ The second part of the hypothesis is supported by the fact that, in some cases, inhibitors of the enzyme that regulates cholesterol synthesis, hydroxymethylglutaryl CoA reductase, are used for treatment. ${ }^{30}$ We have been able to corroborate our hypothesis that the livers of morbidly obese patients show increased levels of HL activity and mRNA in the liver. Moreover, we have not only detected the LPL activity in the livers from obese patients but also the presence of the mRNA of the enzyme. From this evidence, we can deduce that, indeed, the presence of both elevated enzymes in the livers of morbidly obese individuals may cause the liver steatosis detected in these patients. ${ }^{46,50} \mathrm{We}$ also observed that improving the lipid profile in the liver of these obese individuals after bariatric surgery is accompanied by reduced activity of these enzymes as well as the disappearance of the LPL mRNA..$^{46,50}$
HL expression is regulated predominantly by cell cholesterol content (through a sterol response element in its promoter region), steroid and thyroid hormones and possibly glucose and/or insulin, although in adult humans, HL responsiveness to insulin remains controversial. $^{74,75}$ As we have been able to demonstrate in this work, HOMA-IR, a parameter that indicates insulin resistance, was correlated with HL activity in the liver, so that the decrease in insulin resistance during weight loss in obese patients after surgery was accompanied by diminished HL activity in the liver. Some, ${ }^{76,77}$ but not all, ${ }^{78}$ in vitro studies have shown a stimulatory effect of insulin on HL secretion from hepatocytes, and regulation of the HL gene by insulin or insulin resistance has not been conclusively demonstrated. ${ }^{74}$ Moreover, as we have seen, the HL in the liver is also correlated with BMI, body weight and body fat.

\section{Thromboembolism and obesity}

Apart from the specific metabolic alterations, metabolic syndrome is characterized by the presence of a highly prothrombotic state resulting from a combination of increased thrombin generation, platelet hyperactivity and decreased fibrinolysis. ${ }^{79,80}$ The presence of a prothrombotic state accounts in part for the high prevalence of cardiovascular events in patients with visceral obesity, despite the control of traditional risk factors. ${ }^{81}$ Recent studies have focused attention on the pathogenetic role of platelet hyperactivation, ${ }^{82,83}$ and reduced sensitivity to antiaggregating therapy in these conditions mediates the ADP-induced platelet activation. ${ }^{84}$ In conditions of insulin resistance, such as central obesity, type 2 diabetes mellitus with obesity and essential arterial hypertension, a large reduction of platelet sensitivity to the antiaggregating effects of insulin has been reported. ${ }^{85-87}$

In morbidly obese patients undergoing bariatric surgery, there is a high risk of developing a pulmonary embolism or post-thrombotic ${ }^{8}$ syndrome. However, the limited number of studies has not determined the causes of this additional post-surgical complication, but it has been shown that BMI caused an increase in PAI-1 (plasminogen inhibiting factor), the main inhibitor of fibrinolysis, and created a prothrombotic state. The origin of PAI appears to be due to production within the fat. ${ }^{21}$ Moreover, research on the role of genetics in the regulation of thermogenesis and the development of morbid obesity opens very interesting alternatives for the management and treatment of morbidly obese patients. ${ }^{4}$

In our morbidly obese patients, the PAI- 1 obese value was $16217 \mathrm{ng} / \mathrm{mL}$, and this parameter decreased 37\% during first month and reached $356 \mathrm{ng} / \mathrm{mL}$ one year after surgery. Surgery leads to a normalization of the hematological profile and a decrease in PAI-1 levels, which entails a decrease of risk for cardiovascular disease. ${ }^{88}$

\section{Satiety factors and obesity}

Due to the enormous impact of obesity and its associated disorders on health, much effort has been devoted to understanding the control of food intake. In recent years, a large number of molecules have been shown to be involved in energy homeostasis and related to the regulation of body weight. Among the many molecules that have been investigated, we will highlight leptin molecules. Currently, it is believed that the role of leptin is to prevent obesity by regulating intake and thermogenesis through the hypothalamic pathway. In fact, it appears that leptin deficiency causes severe obesity and hyperphagia 
despite the fact that insulin levels are high. In contrast, the deficiency of insulin does not produce obesity, even though in some cases of uncontrolled diabetes mellitus food intake is dramatically increased. ${ }^{89}$

Leptin controls lipid homeostasis in non-adipose tissue during periods of over-nutrition. Although the WAT is the major site of leptin synthesis, it is also synthesized in other tissues such as brown adipose tissue. Moreover, there is a high correlation between circulating levels of leptin and body mass index. This hormone has pleiotropic effects, acting both in the central nervous system and in various peripheral tissues in which it has different functions. ${ }^{90}$ When adipocytes store excess calories in the form of TAG, leptin secretion increases to prevent the accumulation of lipids in non-adipose tissues that are not adapted to excess TAG. However, when leptin is deficient or there is leptin resistance, over-nutrition causes disease in non-adipose tissues that leads to generalized steatosis, lipotoxicity and lipoapoptosis. ${ }^{91}$ Indeed, in obese rats, hyperleptinemia has been shown to prevent excessive lipogenesis and increased oxidation of $\mathrm{FA},{ }^{92}$ although a contrary opinion ${ }^{93}$ has been described, in which some genes involved in the regulation of FA metabolism are stimulated even in leptindeficient mice, and the protein that mediates this regulation could be the apolipoprotein AIV. ${ }^{94}$

It has been described in obese or morbidly obese women that both leptin and TNF-alpha are overexpressed in SAT proportionally to the magnitude of fatty deposits and regardless of the presence of type 2 diabetes. $^{35}$

In the plasma of the morbidly obese, we have seen that the concentration of leptin is very high ( $147 \%$ more than normal); however, one month after bariatric surgery, the levels of leptin decrease and even fall below normal a year after surgery. ${ }^{95}$ Contrary to other reports, ${ }^{96}$ leptin levels were correlated with BMI, the total fat percentage, subcutaneous fat, and visceral fat, both in the obese state and after surgery. Moreover, the progressive decrease in plasma leptin levels did not appear to depend on the type of diet or the number of calories ingested.

However, in addition to leptin, it has been proposed that adipostat, TNF-alpha, apolipoprotein AIV (apoAIV), NPY (neuropeptide Y), ghrelin and CRH (corticotropin-releasing hormone), among others, are also involved in energy homeostasis.

Kern and colleagues have observed that the expression of TNFalpha in human patients with morbid obesity, but without diabetes, is decreased, suggesting that this cytokine may act like adipostat and regulate fat deposition. ${ }^{97}$ It has also been observed that women with morbid obesity overexpress TNF-alpha in subcutaneous adipose tissue in proportion to the magnitude of fatty deposits and regardless of the presence or absence of type 2 diabetes. ${ }^{35}$ In obese patients undergoing weight loss, it has been shown that LPL activity is increased in the WAT by $411 \%$, although this increase is not parallel with the decrease of TNF-alpha, which would agree with the inhibitory effect this cytokine has on LPL in WAT. ${ }^{97}$

The peptide hormone ghrelin is a more recent discovery and has been identified as a secretagogue endogenous growth hormone. In rats, it appears that intraventricular brain injection of ghrelin stimulates intake, increased body weight and fat deposition, which indicates that it is a new regulator of nutritional homeostasis. ${ }^{98}$ Endocrine cells of the stomach mucosa and intestine produce ghrelin, ${ }^{99}$ and insulin is a physiological and dynamic modulator of plasma levels of ghrelin. ${ }^{100}$
Recently, in patients undergoing weight loss, reduced ghrelin levels have been demonstrated, which show that the reversible suppression of this hormone is associated with obesity. The fact that it can be easily measured in plasma provides a new tool to investigate the complex hormonal regulation that governs appetite and energy balance. ${ }^{101}$

In our study ${ }^{95}$ the disappearance of a large part of the stomach after RYGBP was likely not enough to result in reduced plasma ghrelin; the stomach was reduced to about $200 \mathrm{~cm}^{3}$, but a portion of the fundus might have remained active. Additionally, ghrelin levels were lower in morbidly obese patients than in NW subjects but increased to NW levels during weight loss. We therefore consider that loss of the fundus likely did not cause the reduction of ghrelin levels because this effect was not seen at all times studied..$^{95}$ In the present study, ghrelin levels were significantly correlated not only with weight loss but also with decreased insulin resistance; these results are in accordance with previous studies. ${ }^{102,103}$

ApoAIV has an important role in lipoprotein metabolism, including modulation of the catabolism of TAG-rich lipoproteins and reverse transport of cholesterol and cholesterol ester transfer protein (CETP), which is a protein synthesized in the human intestine. The increase in plasma levels of apoAIV is associated with increased prevalence of macrovascular disease in diabetes, not insulin dependence. ${ }^{104}$ It has also been shown that apoAIV increases LPL activation in the presence of lipoproteins, and its presence has been proposed to be necessary for the efficient release of the cofactor of LPL, apoCll, both in HDL and VLDL, which allows LPL to hydrolyze TAG from new QM and VLDL. ${ }^{105}$ In the murine mutation (fld/fld) called fatty liver dystrophy, some markers of the disease have been identified, such as increased serum and liver levels of TAG, increased levels of apoAIV and apoCll mRNAs in the liver, as well as a decrease in the levels of lipolytic activity, LPL and HL. ${ }^{106}$ Some of the apoAIV mutational variants have been associated with increased BMI and fat deposition. ${ }^{107}$ In 1992, it was demonstrated that apoAIV is a satiety signal secreted by the small intestine in response to lipid ingestion, ${ }^{108}$ suggesting that leptin regulates circulating levels of this protein by abolishing synthesis in the small intestine. ${ }^{109}$

In our study, morbidly obese patients had apoAIV levels similar to those of NW individuals, but, as with HDL, levels decreased by $50 \%$ within one month after surgery. ${ }^{95}$ This decrease was not only related to reduced duodenum size, as the duodenum is not the primary source of apoAIV; rather, the observed decrease in apoAIV was likely the result of the general decrease (not only lipids, which stimulate the apoAIV secretion) in caloric ingestion. ${ }^{110}$ We observed one month after surgery that plasma apoAIV levels began to increase until they reached NW levels. ${ }^{95}$ Similarly, HDL levels increased. ${ }^{95}$ However, during this period, patients did not increase their lipid ingestion. Therefore, the change in apoAIV levels may have resulted from increased total intestinal absorption due to increased numbers of enterocytes or development of vellosities. Although not addressed in the present study, our research group has previously described that, in human intestinal atrophy, plasma apoAIV diminishes ${ }^{111}$ due to reduced activity or numbers of enterocytes. The present HDL and apoAIV data further reinforce the concept that human plasma apoAIV is synthesized exclusively by the intestine and is at least partly associated with HDL as previously described. ${ }^{112}$

Some investigators ${ }^{113}$ studying weight loss in children and obese adolescents given a low-fat diet did not observe any relationship 
between plasma levels of apoAIV and TAG; this finding agrees with our data. However, the same study found no correlation between levels of apoAIV and changes in BMI or plasma leptin, in contrast to our findings. In ob/ob mice and human small intestine epithelial CACO-2 cells, respectively, Shen and coworkers ${ }^{114}$ and Morton and coworkers ${ }^{115}$ observed decreased apoAIV levels after leptin administration. We also found a relationship between leptin and apoAIV levels; women had higher plasma leptin and lower apoAIV levels, and men showed the opposite trend. Thus, circulating leptin levels increase as individuals become more obese, whereas the intestinal apoAIV response to lipids is attenuated:116 during weight loss, this situation is reversed. It is possible, as suggested by other investigators, that the effects of leptin and apoAIV combine, perhaps synergistically, to reduce food intake. ${ }^{114}$ In the present study, plasma apoAIV levels significantly varied between women and men at all times after surgery. Men had higher apoAIV levels than women $(p<0.05)$, and gender explained $10 \%$ of the variance in plasma apoAIV levels. The study of changes in plasma levels of leptin, ghrelin and apoAIV after surgery might allow better diagnosis of fat loss and recovery of gastrointestinal function, which is important for clinical monitoring of patients.

\section{Stress and obesity}

Stress is a widespread phenomenon in the population, and it is independent to social class. Stress can be defined as an organism's response, which developed through phylogeny, in response to danger. ${ }^{17}$ The individual response is activated when the stimulus exceeds the subjective capacity of homeostatic mechanisms to confront the disruption of the internal environment. Every phenomenon has a physical component, determined by the nature or origin of the stress phenomenon, and another psychological component, which refers to how the body perceives this stimulus. The primary response to stress consists of the activation of the hypothalamic (CRF)-pituitary (ACTH)-adrenal (glucocorticoids) axis. ${ }^{118}$ Glucocorticoids stimulate the synthesis and release of catecholamines, especially in the adrenal medulla. Both circulating glucocorticoids and catecholamines reach the target tissues and prepare to confront the danger. The main metabolic abnormalities were hyperglycemia, increased lipolysis, increased heart rate and blood pressure, etc. Although it is known that stress is a risk factor in the development of atherosclerosis, little is known about its effect on lipid metabolism and LPL and HL activities. The existing literature regarding the effect of stress on lipid metabolism ${ }^{119,120}$ is sparse and, in the case of LPL, contradictory. ${ }^{121-123}$ It has been described in rats, in vivo and in vitro that adrenaline causes a decrease in the LPL activity in the vascular bed of adipocytes, but expression of the gene encoding the enzyme was not affected, ${ }^{124}$ in parallel with an increase in plasma LPL activity as well as the appearance of LPL activity in the liver, ${ }^{125,126}$ but there is still controversy about the regulatory mechanism. This study showed that adrenaline or isoproterenol increased the release of LPL activity in the plasma and the incubation medium, and it discussed the possible mechanism by which catecholamines exert this effect.

To further the knowledge of LPL in vivo regulation by adrenaline, a model of restraint stress in rats was used and applied either as chronic and acute conditions. ${ }^{127}$ A method for lipoprotein isolation by differential ultracentrifugation and quantification [128] has been modified and adapted for small volumes of plasma to study the possible effects of stress on lipid metabolism. Using these tools, both chronic and acute stresses were reported to produce significant alterations in lipid and lipoprotein metabolism, ${ }^{127}$ and these changes were accompanied by a decrease in LPL activity in white adipose tissue (epididymal, mesenteric and lumbar) and an increase in plasma. ${ }^{124}$ The possible role of blood flow in the regulation of LPL by catecholamines has also been studied. Because of its intravascular location, it is possible that LPL is sensitive to variations in the flow of blood through the capillaries. Thus, an increased flow could lead to an increase in the release of LPL from its anchor, which would lead to a decline in activity in the tissue without altering its synthesis. This would provide a mechanism for short-term regulation of the LPL (much faster than the regulation of enzyme synthesis), which has not been studied yet. It has recently been reported that acute immobilization stress increased blood flow in white adipose tissue (which reduces LPL activity) but not in muscle (in which LPL was unchanged). ${ }^{129}$

It has also been reported that LPL shows a circadian rhythm in adult rats ${ }^{130}$ that can be modified by soft stress. ${ }^{131}$ However, there are very few data linking stress caused by with lipolytic activity. In experimental animals, HL activity and mRNA were shown to decrease in the liver after hepatectomy, whereas activity was not detected in the plasma. However, adrenal HL activity did not vary post-surgery. ${ }^{132}$ This is very interesting because the steroidogenic organs, such as the adrenal gland, cannot synthesize the enzyme, which originates in the liver; however, given the need to capture cholesterol for the synthesis of catecholamines and glucocorticoids, such as in a stressful situation, steroidogenic organs retain high levels of HL. It has also been observed that surgical stress leads to the recovery of the LPL activity and mRNA in the liver, and there are also changes in the expression of LPL and other proteins, such as albumin, actin, etc., in peripheral tissues. ${ }^{133}$ Today, we tend to view the psychopathology of obesity as a consequence more than as a cause of obesity. Despite this positive point of view, the obese continue to suffer prejudice and discrimination in everyday life. Adverse psychosocial effects, together with the high incidence of cardiovascular disease and diabetes with morbid obesity, call dramatically for obesity treatment. ${ }^{134}$ The psychopathological profiles of the morbidly obese before surgery show depression, feelings of insecurity and despair, somatization, denial of emotional stress, difficulties in interpersonal relationships, poor social adjustment and low self-esteem. After surgery, improvement is determined by the psychological effect of weight loss and even the occasional surgical complications, yet, despite the complications, these patients have less mental and emotional suffering. Apparently, these patients prefer a non-obese state with surgical complications to the obese state. ${ }^{134}$ Recently it has been suggested that adverse psychological states associated with chronic stress may lead to visceral obesity. ${ }^{135}$

A great portion of studies done on lipoproteins and/or lipolytic activity (LPL, HL, HSL) and obesity have been conducted in obese or morbidly obese patients undergoing different kinds of surgery (mostly cholecystectomy) who, additionally, have participated in adipose tissue biopsies. ${ }^{136}$ But studies on the obese or morbidly obese undergoing bariatric surgery in which the stress of surgery has been added to a sharp weight loss, which can lead to significant changes in metabolism, are scarce. The extracellular localization of LPL clearly affects the mechanisms through which it could be regulated, such as allostery, phospho-dephosphorylation, etc. Several authors have concluded that LPL is regulated in the short term primarily through 
changes in its synthesis and intracellular processing. ${ }^{137}$ This seems particularly true in the changes that nutritional status of the individuals causes in the LPL activity of different tissues. ${ }^{138}$ However, changes that occur in other situations, such as stress, may use other control mechanisms that have not yet been described. Catecholamines can be seen as negative regulators of LPL in WAT for two reasons: first, adrenergic stimulation by catecholamines of the pancreas decreases insulin secretion, which potentially eliminates or reduces LPL in WAT; second, catecholamines and other modulators that increase cAMP levels decrease LPL activity by accelerating the inactivation or degradation of LPL inside adipocytes. ${ }^{139}$ Thus, people who have both an LPL and/or HL decrease and obesity have an increased risk for cardiovascular diseases. ${ }^{140}$

In population studies, adrenal hormones show strong statistical associations with centralization of body fat as well as obesity. There is considerable evidence from clinical, cellular and molecular studies that elevated cortisol, particularly when combined with secondary inhibition of sex steroids and secreted growth hormones, causes accumulation of fat in visceral adipose tissues as well as metabolic abnormalities (know as metabolic syndrome). Hypertension is probably due to a parallel activation of the central sympathetic nervous system. Depression and 'small baby syndrome' as well as stress exposure in men and non-human primates are followed with time by similar central and peripheral abnormalities. Glucocorticoid exposure is also followed by increased food intake and 'leptin resistant' obesity, perhaps by disrupting the balance between leptin and neuropeptide $\mathrm{Y}$ to the advantage of the latter. The consequence might be 'stress eating', which is a poorly defined entity. Factors that activate the stress centers in humans include psychosocial and socioeconomic handicaps, depressive and anxiety traits, alcohol and smoking, with some differences in profiles between personalities and genders. Polymorphisms have been defined in several genes associated with the cascade of events along the stress axes. Based on this evidence, it has been suggested that environmental, perinatal and genetic factors induce neuroendocrine perturbations that are followed by abdominal obesity with its associated comorbidities. ${ }^{141}$

We have demonstrated, in rats ${ }^{142}$ and mice ${ }^{143}$ subjected to different types of stress, that the activities of HL in the liver, plasma and the adrenal glands are correlated, so that an increase in HL activity in the adrenal gland (which, at least in rodents, does not synthesize the enzyme ${ }^{144}$ ) allows cholesterol to be captured in order to synthesize steroid hormones, as in the case of corticosterone. In the present work, we demonstrated, for the first time, that levels of both ACTH and cortisol were very high in obese individuals and that these levels decreased with weight loss. There are conflicting data regarding the levels of cortisol in obese humans; it has been described that they may be increased, ${ }^{145}$ decreased ${ }^{146}$ or normal. ${ }^{147}$ As for the synthesis of steroid hormones in the adrenal glands, cholesterol is essential; we believe that, as in the animals, in humans, the enzyme HL might facilitate cholesterol uptake from the corresponding lipoproteins. Both the active and the inactive forms of HL in the plasma travel in association with HDL to the adrenal glands to facilitate the uptake of cholesterol by these glands or other steroidogenic organs, as we demonstrated in rats. ${ }^{148}$ The fact that we have determined the activity of HL in plasma without heparin and that this correlated with the enzyme activity in the liver allows us to hypothesize that the enzyme is released from the liver and taken up by the adrenal glands for the synthesis of steroid hormones. The administration of heparin released HL from both the liver and the adrenal or sexual organs, so it is not possible to know how much enzyme is free in the plasma and how much has been released from other organs.

\section{Conclusion}

Despite the extensive research on obesity in recent decades, much remains to be elucidated. Hopefully in subsequent years we can increase awareness of this disease in developed countries, not only because it is harmful in itself but also because it is associated with many comorbidities.

\section{Acknowledgements}

The authors have declared that no conflict of interest exists. The authors who have taken part in this study do not have a relationship with the manufacturers of the drugs involved, either in the past or present, and did not receive funding from the manufacturers to carry out their research. The English grammar has been corrected by American Journal Experts (www.journalexperts.com).

This work was supported by Ministerio de Sanidad y Consumo, Instituto de Salud Carlos III (ISCIII) (PI15/00190 to JP-O PI15/00332 to JAB-F) and FEDER Funds of the EU (Fondo Europeo de Desarrollo Regional: "Una manera de hacer Europa").

\section{Conflict of interest}

The author declares that there is none of the conflicts.

\section{References}

1. Williams EP, Mesidor M, Winters K, et al. Overweight and Obesity: Prevalence, Consequences, and Causes of a Growing Public Health Problem. Current Obes Reports. 2015;4(3):363-370.

2. Albrecht RJ, Pories WJ. Surgical intervention for the severely obese. Baillieres Best Pract Res Clin Endocrinol Metab. 1999;13(1):149-172.

3. Sturm R, Hattori A. Morbid obesity rates continue to rise rapidly in the United States. Int J Obes (Lond). 2013;37(6):889-891.

4. Basterra-Gortari FJ, Beunza JJ, Bes-Rastrollo M, et al. Increasing trend in the prevalence of morbid obesity in Spain: from 1.8 to 6.1 per thousand in 14 years. Rev Esp Cardiología. 2011;64(5):424-426.

5. Flegal, KM. The effects of changes in smoking prevalence on obesity prevalence in the United States. Am J Public Health 2007;97(8):1510-1514

6. Lewis GF, Carpentier A, Adeli K, et al. Disordered fat storage and mobilization in the pathogenesis of insulin resistance and type 2 diabetes. Endocr Rev. 2002;23(2):201-229.

7. Björntorp P. Do stress reactions cause abdominal obesity and comorbidities? Obes Rev. 2001;2(2), 73-86.

8. Wajchenberg BL. Subcutaneous and visceral adipose tissue: their relation to the metabolic syndrome. Endocr Rev. 2000;21(6):697-738.

9. Deitel M. Overview of operation for morbid obesity. World J Surg. 1998;22(9):913-918.

10. Davies PJA, Berry SA, Shipley GL, et al. Metabolic effects of rexinoids: tissue-specific regulation of lipoprotein lipase activity. Molecular Pharmacol. 2001;59(2):170-176. 
11. Raspé E, Madsen L, Lefebvre AM, et al. Modulation of rat liver apolipoprotein gene expression and serum lipid leves by thetradecylthioacetic acid (TTA) via PPAR activation. J Lipid Res. 1999;40(11):2099-2110.

12. Leibowitz MD, Fiévet C, Hennuyer N, et al. Activation of PPAR alters lipid metabolism in dbldb mice. FEBS lett. 2000;473(2):333-336.

13. Sanchis D, Balada F, Grasa MM, et al. Oleoyl-estrone induces the loss of body fat in rats. Int J Obes Relat Metab Disord. 1996;20(6):588-594

14. Peinado-Onsurbe J, Blay M, Casadomé L, et al. Effect of 24-h food deprivation on lipoprotein composition and oleoyl-estrone content of lean and obese zucker rats. Eur J Nutr. 2001;40(4):155-160.

15. Alemany M, Blay M, Peinado-Onsurbe J, et al. Effect of oral oleoylestrone treatment on plasma lipoproteins and tissue lipase activities of Zucker lean and obese rats. Int J Obesity. 2001;26:618-626.

16. Blay M, Peinado-Onsurbe J, Julve J, et al. Anomalous lipoproteins in obese zucker rats. Diabetes Obes Metabo. 2001;3(4):259-270.

17. Peinado-Onsurbe J, Blay M, Julve J, et al. Lipoprotein lipase and cholesterol transfer activities of lean and obese Zucker rats. Horm Metab Res. 2001;33(8):458-462.

18. Virgili J, Casals I, Peinado-Onsurbe J, et al. Distribution of oleoylestrone in rat plasma lipoproteins. Horm Metab Res. 1999;31:597-601.

19. Schoonjans K, Peinado Onsurbe J, Heyman RA, et al. PPARalpha and PPAR $-\gamma$ activators direct a distinct tissue-specific transcriptional response via a PPRE in the lipoprotein lipase gene. Embo J. 1996;15(19):5336-5348

20. Schoonjans K, Peinado Onsurbe J, Fruchart JC, et al. 3-Hydroxy-3methylglutaryl CoA reductase inhibitors reduce serum triglyceride levels through modulation of apolipoprotein C-III and lipoprotein lipase. FEBS Lett. 1999;452(3):160-164.

21. Robinson DS. The function of triglycerides in fatty acid transport. Comp Biochem. 1970;18:51-116.

22. Fielding B, Frayn K. Lipoprotein lipase and disposition of dietary fatty acids. Br J Nutrition. 1998;80(6):495-502.

23. Olivecrona T, Bengtsson-Olivecrona G. Lipoprotein lipase from milk. The model enzyme in lipoprotein lipase research. In: Borensztajn editor. Lipoprotein lipase. USA: Chicago, Evener Publishers Inc; p. 1987. 15-58.

24. Vilella E, Joven J, Fernández M, et al. Lipoprotein lipase in human plasma is mainly inactive and associated with cholesterol-rich lipoproteins. $J$ Lipid Res. 1993;34(9):1555-1564.

25. Vilaró S, Llobera M, Bengtsson-Olivecrona G, et al. Lipoprotein lipase uptake by the liver: localization turnover and metabolic role. Am J Physiol. 1988;254(5 Pt 1):711-722.

26. Camps L, Reina M, Llobera M, et al. Lipoprotein lipase: cellular origin and functional distribution. Am J Physiol. 1990;258(4 Pt 1):73-81.

27. Goldberg IJ. Lipoprotein lipase and lipolysis: central roles in lipoprotein metabolism and atherogenesis. Review. J Lipid Res. 1996;37(4):693-707.

28. Eckel RH. Adipose tissue lipoprotein lipase. In: Borensztajn editor. Lipoprotein lipase. USA: Chicago, Evener Publishers Inc; 1987. p. 79-132.

29. Olsson SA, Petersson BG, Sorbris R, et al. Effects of weight reduction after gastroplasty on glucose and lipid metabolism. Am J Clin Nutr. 1984;40(6):1273-1280.

30. Bosello O, Cigolini M, Battaggia A, et al. Adipose tissue lipoproteinlipase activity in obesity. Int J Obesity. 1984;8:213-220.
31. Taskinen MR, Nikkilá EA. Lipoprotein Lipase of Adipose Tissue and Skeletal Muscle in Human Obesity: Response to Glucose and to Semistarvation. Metabolism. 1981;30(8):810-817.

32. Taskinen, MR, Nikkilá, EA. Lipoprotein lipase activity in adipose tissue and in postheparin plasma in human obesity. Acta Med Scand. 1977;202(1-6):399-408.

33. Kern PA, Ong JM, Saffari B, et al. The effects of weight loss on the activity and expression of adipose-tissue lipoprotein lipase in very obese humans. N Engl J Med. 1990;322(15):1053-1059.

34. Ong JM, Kern PA. Effect of feeding and obesity on lipoprotein lipase activity immunoreactive protein and messenger RNA levels in human adipose tissue. J Clin Invest. 1989;84(1):305-311.

35. Bulló M, García-Lorda P, Peinado-Onsurbe J, et al. TNF expression of subcutaneous adipose tissue in obese and morbid obese females relationship to adipocyte LPL activity and leptin synthesis. Int J Obesity. 2002;26(5):652-658.

36. Marin P, Andersson B, Ottosson M, et al. The morphology and metabolism of intraabdominal adipose tissue in men. Metabolism. 1992;41(11):1242-1248.

37. Rebuffe-Scrive M, Andersson B, Olbe L, et al. Metabolism of adipose tissue in intraabdominal depots of nonobese men and women. Metabolism. 1989;38(5):453-458.

38. Meisner H, Tenney K. $\mathrm{pH}$ as an indicator of free fatty acid release from adipocytes. J Lipid Res. 1977;18(6):774-776.

39. Large V, Reynisdottir S, Langin D, ET AL. Decreased expression and function of adipocyte hormone-sensitive lipase in subcutaneous fat cells of obese subjects. J Lipid Res. 1999;40(11):2059-2066.

40. Pardina E, Lecube A, Llamas R, et al. Lipoprotein Lipase but Not Hormone-Sensitive Lipase Activities Achieve Normality After Surgically Induced Weight Loss in Morbidly Obese Patients. Obes Surg. 2009;19(8):1150-1158.

41. Kolehmainen M, Vidal H, Ohisalo JJ, et al. Hormone sensitive lipase expression and adipose tissue metabolism show gender differences in obese subjects after weight loss. Int $J$ Obes Relat Metab Disord. 2002;26(1):6-16

42. Frayn KN, Coppack SW, Fielding, BA, Humphreys, SM. Coordinated regulation of hormone-sensitive lipase and lipoprotein lipase in human adipose tissue in vivo: implications for the control of fat storage and fat mobilization. Adv Enzyme Regul. 1995;35:163-178.

43. Löfgren P, Hoffstedt J, Rydén M, et al. Major gender differences in the lipolytic capacity of abdominal subcutaneous fat cells in obesity observed before and after long-term weight reduction. J Clin Endocrinol Metab. 2002;87(2):764-771.

44. Després JP, Ferland M, Moorjani S, et al. Role of hepatic-triglyceride lipase activity in the association between intra-abdominal fat and plasma HDL cholesterol in obese women. Arteriosclerosis. 1989;9(4):485-492.

45. Weisweiler P. Plasma Lipoproteins and Lipase and Lecithin: Cholesterol Acyltransferase Activities in Obese Subjects Before and After Weight Reduction. Biochem J. 1987;65(5):969-973.

46. Pardina E, Baena-Fustegueras JA, Catalán R, et al. Increased expression and activity of hepatic lipase in the liver of morbidly obese adult patients in relation to lipid content. Obes Surg. 2009;19(7):894-904.

47. Kobayashi J, Hashimoto H, Fukamachi I, et al. Lipoprotein lipase mass and activity in severe hypertriglyceridemia. Clin Chim Acta 1993;216(1-2):113-123. 
48. Sorbris R, Petersson BG, Nilsson-Ehle P. Effects of weight reduction on plasma lipoproteins and adipose tissue metabolism in obese subjects. Eur J Clin Invest. 1981;11(6):491-498.

49. Purnell JQ, Kahn SE, Albers JJ, et al. Effect of Purnell JQ, Kahn SE, Albers JJ, et al. Effect of weight loss with reduction of intra-abdomina fat on lipid metabolism in older men. J Clin Endocrinol Metab. 2000;85(3):977-982

50. Pardina E, Baena-Fustegueras JA, Llamas R, et al. Lipoprotein Lipase Expression in Livers of Morbidly Obese Patients Could be Responsible for Liver Steatosis. Obes Surg. 2009;19(5):608-616.

51. Poniachik J, Mancilla C, Contreras J, et al. Obesity: risk factor for steatohepatitis and hepatic fibrosis. Rev Med Chile. 2002;130(7):731-736.

52. Crespo J, Fernandez-Gil P, Hernandez-Guerra M, et al. Are there predictive factors of severe liver fibrosis in morbidly obese patients with non-alcoholic steatohepatitis? Obes Surg. 2001;11(3):254-257.

53. Purnell JQ, Kahn SE, Albers JJ, et al. Effect of weight loss with reduction of intra-abdominal fat on lipid metabolism in older men. $J$ Clin Endocrinol Metab. 2000;85(3):977-982

54. Pardina E, Baena-Fustegueras JA, Llamas R, et al. Lipoprotein Lipase Expression in Livers of Morbidly Obese Patients Could be Responsible for Liver Steatosis. Obes Surg. 2009;19(5):608-616.

55. Poniachik J, Mancilla C, Contreras J, et al. Obesity: risk factor for steatohepatitis and hepatic fibrosis. Rev Med Chile. 2002;130(7):731-736

56. Crespo J, Fernandez-Gil P, Hernandez-Guerra M, et al. Are there predictive factors of severe liver fibrosis in morbidly obese patients with non-alcoholic steatohepatitis? Obes Surg. 2001;11(3):254-257.

57. Vilaró S, Llobera M, Bengtsson-Olivecrona G, et al. Synthesis of lipoprotein lipase in the liver of newborn rats and localization of the enzyme by immunofluorescence. Biochem J. 1988;249(2):549-556.

58. Grinberg DR, Ramírez I, Vilaró S, et al. Starvation enhances lipoprotein lipase activity in the liver of the newborn rat. Biochim Biophys Acta. $1985 ; 833(2): 1217-1222$

59. López-Tejero D, Llobera M, Herrera E. High liver lipoprotein lipase activity in hyperlipemic developing rats from undernourished pregnant mothers. Biosci Rep. 1988;8(4):309-314.

60. Peinado J, Martínez JV, Vilanova J, et al. Effect of starvation on lipoprotein lipase activity in the liver of de veloping rats. Biochim Biophys Acta. 1990;1043(1):7-11.

61. Burgaya F, Peinado J, Vilaró S, et al. Lipoprotein lipase activity in neonatal-rat liver cell types. Biochem J. 1989;259:159-166.

62. Peinado-Onsurbe J, Staels B, et al. Neonatal Extinction of Liver Lipoprotein Lipase Expression. Biochim Biophys Acta. 1992;1131(3):281-286.

63. Peinado-Onsurbe J, Soler C, Soley M, et al. Lipoprotein Lipase and Hepatic Lipase Activities Are Differentially Regulated in Isolated Hepatocytes from Neonatal Rats. Biochim Biophys Acta. 1992;(1125):82-89.

64. Giménez-Llort L, Vilanova J, Skottova N, et al. Lipoprotein lipase enables triacylglycerol hydrolysis by perfused newborn rat liver. Am J Physiol. 1991;261(4):641-647.

65. Vilaró S, Reina M, Ramírez I, et al. Intralipid administration induces a lipoprotein lipase-like activity in the livers of starved adult rats. Biochem J. 1986;236(1):273-278.

66. Vilaró S, Ramírez I, Bengtsson-Olivecrona G, et al. Lipoprotein lipase in liver Release by heparin and immunocytochemical localization. Biochim Biophys Acta. 1988;959(2):106-117.
67. Vilaró S, Testar X, Ramírez I, et al. Lipoprotein lipase activity in the liver of starved pregnant rats. Biol Neonate. 1990;57(1):37-45.

68. Sabugal R, Robert QM, Julve J, et al. Hepatic regeneration induces changes in lipoprotein lipase activity in several tissues and its reexpression in the liver. Biochem J. 1986;318(2):597-602.

69. Vilaró S, Llobera M, Bengtsson-Olivecrona G, et al. Lipoprotein lipase uptake by the liver: localization turnover and metabolic role. Am J Physiol. 1988;254(5):711-722.

70. Wanless IR, Lentz JS. Fatty liver hepatitis (steatohepatitis) and obesity: an autopsy study with analysis of risk factors. Hepatology. 1990;12(5):1106-1110.

71. Reid AE. Nonalcoholic steatohepatitis. Gastroenterology. 2000;(121):710-723.

72. Angulo P, Keach JC, Batts KP, et al. Independent predictors of liver fibrosis in patients with nonalcoholic steatohepatitis. Hepatology. 1999;30(6):1356-1362.

73. Perret B, Mabile L, Martinez L, et al. Hepatic lipase: structure/function relationship synthesis and regulation. JLipid Res. 2002;43(8):1163-1169.

74. Deeb S, Zambon SA, Carr MC, et al. Hepatic lipase and dyslipidemia: interactions among genetic variants obesity gender and diet. J Lipid Res. 2003;44(7):1279-1286.

75. Emmison N, Zammit VA, Agius L. Triacylglycerol accumulation and secretion in hepatocyte cultures. Effects of insulin albumin and Triton WR 1339. Biochem J. 1992;285(2):655-660.

76. Yoon TH, Yamada N, Ishibashi S. The release of hepatic triglyceride lipase from rat monolayered hepatocytes in primary culture. Endocrinol Jpn. 1990;37(3):437-442.

77. Morita T, Sakata K, Kanagawa A, et al. Stimulatory release of hepatic lipase activity from cultured rat hepatocytes by sodium orthovanadate: rapid increase in cyclic adenosine monophosphate content. Biol Pharm Bull. 1994;17(5):577-580.

78. Mertens I, Van Gaal LF. Obesity, haemostasis and the fibrinolytic system. Obes Rev. 2002;3(2):85-101.

79. Nieuwdorp M, Stroes ES, Meijers JC, et al. Hypercoagulability in the metabolic syndrome. Curr Opin Pharmacol. 2005;5(2):155-159.

80. Ades PA, Savage PD, Toth MJ, et al. The influence of obesity and consequent insulin resistance on coronary risk factors in medically treated patients with coronary disease. Int J Obes. 2008;32(6):967-974.

81. Vinik AI, Erbas T, Park TS, et al. Platelet dysfunction in type 2 diabetes. Diabetes Care. 2001;24(8):1476-1485.

82. Colwell JA, Nesto RW. The platelet in diabetes: focus on prevention of ischemic events. Diabetes Care. 2003;26(7):2181-2188.

83. Ferreira IA, Eybrechts KL, Mocking, AI, et al. IRS-1 mediates inhibition of Ca2p mobilization by insulin via the inhibitory G-protein Gi. J Biol Chem. 2004;(279):3254-3264.

84. Anfossi G, Russo I, Trovati M. Platelet resistance to the antiaggregating agents in the insulin resistant states. Curr Diabetes Rev. 2006;(2):409-430.

85. Trovati M, Mularoni EM, Burzacca S, et al. Impaired insulin-induced platelet antiaggregating effect in obesity and in obese NIDDM patients. Diabetes.1995;(44):1318-1322.

86. Ferreira IA, Mocking AI, Feijge MA, et al. Platelet inhibition by insulin is absent in type 2 diabetes mellitus. Arterioscler Thromb Vasc Biol. 2006;(26):417-422. 
87. Pardina E, Baena Fustegueras JA, Catalán R, et al. Evolution and improvement of hematologic profile in morbid obese patients after bariatric surgery. XV International Symposium on Atherosclerosis Junio. 2009;10(2):e1306.

88. Schwartz MW, Woods SC, Porte D, et al. Central nervous system control of food intake. Nature. 2000;(404):661-671.

89. Margetic S, Gazzola C, Pegg GG, et al. Leptin: a review of its peripheral actions and interactions. Int $J$ Obes Relat Metab Disord. 2002;(26):1407-1433.

90. Unger RH. Lipotoxic diseases. Annu Rev Med. 2002;(53):319-336.

91. Lee Y, Wang MY, Kakuma T, et al. Liporegulation in diet-induced obesity. The antisteatotic role of hyperleptinemia. J Biol Chem. 2001;(276):5629-5635.

92. Roden M, Anderwald C, Furnsinn C, et al. Effects of short-term leptin exposure on triglyceride deposition in rat liver. Hepatology. 2000;32(5):1045-1049.

93. Ferrante AW, Thearle M, Liao T, et al. Effects of leptin deficiency and short-term repletion on hepatic gene expression in genetically obese mice. Diabetes. 2001;(50):2268-2278.

94. Pardina E, López-Tejero MD, Llamas R, et al. Ghrelin and Apolipoprotein AIV Levels Show Opposite Trends to Leptin Levels During Weight Loss in Morbidly Obese Patients. Obes Surg. 2009;19(10):1414-1423.

95. Minocci A, Savia G, Lucantoni R, et al. Leptin plasma concentrations are dependent on body fat distribution in obese patients. Int J Obes Relat Metab Disord. 2000;24(9):1139-1144.

96. Kern PA, Saghizadeh M, Ong JM, et al. The expression of tumor necrosis factor in human adipose tissue. Regulation by obesity weight loss and relationship to lipoprotein lipase. J Clin Invest. 1995;5(5):2111-2119.

97. Nakazato M, Murakami N, Date Y, et al. A role for ghrelin in the central regulation offeeding. Nature 2001;409(6817):194-198.

98. Wang G, Lee HM, Englander E, et al.Ghrelin-not just another stomach hormone. Regul Pept. 2002;105(2):75-81.

99. Saad MF, Bernaba B, Hwu CM, et al. Insulin regulates plasma ghrelin concentration. J Clin Endocrinol Metab. 2002;87(8):3997-4000.

100. Hansen TK, Dall R, Hosoda H, et al. Weight loss increases circulating levels of ghrelin in human obesity. Clin Endocrinol. 2002;56(2):203-206.

101. Adami GF, Cordera R, Andraghetti G, et al. Changes in serum ghrelin concentration following biliopancreatic diversion obesity. Obes Res. 2004;12(4):684-687.

102. Kotidis EV, Koliakos G, Papavramidis TS, et al. The effect of biliopancreatic diversion with pylorus-preserving sleeve gastrectomy and duodenal switch on fasting serum ghrelin, leptin and adiponectin levels: is there a hormonal contribution to the weight reducing effect of this procedure? Obes Surg. 2006;16(5):554-559.

103. Verges BL, Lagrost L, Vaillant G, et al. Macrovascular disease is associated with increased plasma apolipoprotein A-IV levels in NIDDM. Diabetes.1997;46(1):125-132.

104. Goldberg IJ, Scheraldi CA, Yacoub LK, et al. Lipoprotein ApoC-11 activation of lipoprotein lipase. Modulation by apolipoprotein A-IV. $J$ Biol Chem. 1990;265(8):4266-4272.

105. Langner CA, Birkenmeier EH, Ben Zeev O, et al. The fatty liver dystrophy (fld) mutation. A new mutant mouse with a developmental abnormality in triglyceride metabolism and associated tissue-specific defects in lipoprotein lipase and hepatic lipase activities. J Biol Chem. 1989;264(14):7994-8003.
106. Lefevre M, Lovejoy JC, De Felice SM, et al. Common apolipoprotein A-IV variants are associated with differences in body mass index levels and percentage body fat. Int J obesity. 2000;24(8):945-953.

107. Fujimoto JA, Cardelli P, Tso P. Increased apolipoprotein AIV in rat mesenteric lymph after lipid meal acts as a physiological signal for satiation. Am J Physiol. 1992;262(6 Pt 1):G1002-1006.

108. Doi T, Liu M, Seeley RJ, et al. Effect of leptin on intestinal apolipoprotein AIV in response to lipid feeding. Am J Physiol Regul Integr Comp Physiol. 2001;281(3):753-759.

109. Hayashi H, Fujimoto K, Cardelli JA, et al. Fat feeding increases size, but not number, of chylomicrons produced by small intestine. Am J Physiol. 1990;259(5):709-719.

110. Través C, Coll O, Cararach V, et al. Clinical approach to intestinal maturation in neonates prenatally exposed to alcohol. Alcohol. 2007;42(5):407-412.

111. Duverger N, Ghalim N, Ailhaud G, et al. Characterization of apoAIV-containing lipoprotein particles isolated from human plasma and interstitial fluid. Arterioscler Thromb. 1993;13(1):126-132.

112. Lingenhel A, Eder C, Zwiauer K, et al. Decrease of plasma apolipoprotein A-IV during weight reduction in obese adolescents on a low fat diet. Int J Obes Relat Metab Disord. 2004;28(11):509-513.

113. Shen L, Tso P, Woods SC, et al. Hypothalamic apolipoprotein AIV is regulated by leptin. Endocrinology. 2007;148(6):2681-2689.

114. Morton NM, Emilsson V, Liu YL, et al. Leptin action in intestinal cells J Biol Chem. 1998;(273):26194-26201.

115. Kalogeris TJ, Painter RG. Adaptation of intestinal production of apolipoprotein A-IV during chronic feeding of lipid. Am J Physiol Regul Integr Comp Physiol. 2001;280(4):R1155-R1161.

116. Vigas N. Contribution to the understanding of the stress concept en Catecholamines and stress: recent advances. In: Ursding E, Kvetnansky R, Koping IJ, editors. NY: Elsevier Noth Holland; 1980. p. 572-578.

117. Martí O, Armario A. Modificacions neuroendocrinológiques amb I'estrés. Neurociència Treballs de la Societat Catalana de Biologia 47th ed. USA: Francesc Artigas; 1996. p. 171-185.

118. Hershock D, Vogel HV. The effects of immobilization stress on serum triglycerides nonesterified fatty acids and total cholesterol in male rats after dietary modifications. Life Sci. 1989;45(2):157-165.

119. Armario A, Montero JL, Balasch J. Sensitivity of corticosterone and some metabolism variables to graded levels of low intensity stresses in adult male rats. Physiol Behav. 1986;37(4):559-561.

120. Borbola J, Gecse A, Karady S. The activity of lipoprotein lipase in rat heart after tourniquet stress. Adv Exp Med Biol. 1972;33:387-393.

121. Ashby P, Robinson DS. Effects of insulin glucocorticoids and adrenaline on the activity of rat adipose-tissue lipoprotein lipase. Biochem J. 1980;188(1):185-192.

122. Hülsman W, Dubelaar ML. Lipoprotein lipase and stress hormones: studies with glucocorticoids and cholera toxin. Biochim Biophys Acta. 1986;875(1):69-75.

123. Ballart X, Siches M, López Tejero D, et al. Isoproterenol increases active lipoprotein lipase in adipocyte medium and in rat plasma. Biochimie. 2003;85(10):971-982.

124. Knobler H, Chajek Shaul T, Stein O, et al. Modulation of lipoprotein lipase in the intact rat by cholera toxin-an irreversible agonist of cyclic AMP. Biochim Biophys Acta. 1984;795(2):363-371. 
125. Ball KL, Speake BK, Robinson DS. Effects of adrenaline on the turnover of lipoprotein lipase in rat adipose tissue. Biochim Biophys Acta. 1986;877(3):399-405.

126. Knobler H, Chajek Shaul T, Stein O, et al. Modulation of lipoprotein lipase in the intact rat by cholera toxin-an irreversible agonist of cyclic AMP. Biochim Biophys Acta. 1984;795(2):363-371.

127. Ricart-Jané D, Rodríguez-Sureda V, Benavides A, et al. Immobilization stress alters intermediate metabolism and circulating lipoproteins in the rat. Metabolism. 2002;51(7):925-931.

128. Rodríguez-Sureda V, Julve J, Llobera M, et al. Ultracentrifugation micromethod for preparation of small experimental animals lipoproteins Analytical Biochem. 2002;303(1):73-77.

129. Ricart-Jané D, Rodríguez-Sureda V, Benavides A, et al. Immobilization stress alters intermediate metabolism and circulating lipoproteins in the rat. Metabolism. 2002;51(7):925-931.

130. Benavides A, Siches, M, Llobera, M. Circadian rhythms of lipoprotein lipase and hepatic lipase activities in the intermediate metabolism of the adult rat. Amer J Physiol. 1998;275(3 PT 2):R811-R817.

131. Abellán R, Benavides A, Díez-Noguera A, et al. Effects of mild stress by isolation on metabolic circadian rhythms in the adult rat. Am J Physiol. $2002 ; 22: 417-422$

132. Sabugal R, Robert MQ, Julve J, et al. Decrease in the expression of hepatic lipase activity following partial hepatectomy. Biochim Biophys Acta. 1996;1302(3):193-198.

133. Palmero E, Ricart D, Llobera M, et al. Partial hepatectomy and/or surgical stress provoke changes in the expression of lipoprotein lipase and actin in liver and extrahepatic tissues. Biochim Biophys Acta. 1999;1441(1):61-68.

134. Van Gemert WG, Severeijns RM, Greve JWM, et al. Psychological functioning of morbidly obese patients after surgical treatment. Int $J$ Obesity. 1998;22(5):393-398.

135. Montague CT, Prins JB, Sanders L, et al. Depotrelated gene expression in human subcutaneous and omental adipocytes. Diabetes. 1998;47(9):1384-1391.

136. Ham JM, Slack WW. Lipoprotein lipase activity in patients before and after minor surgical operations. Clin Chim Acta. 1969;25(3):417-422.
137. Doolittle MH, Ben-Zeev O, Davis RC, et al. Lipases and obesity: posttranslational regulation of lipoprotein lipase. In: Bray GA, Ricquier D, Spiegelman BM, editors. Obesity towards a molecular approach. USA: Wiley-Liss New York; 1990. p. 237-246.

138. Doolittle M, Ben-Zeev O, Elovson J, et al. The response of lipoprotein lipase to feeding and fasting. Evidence for posttranslational regulation. $J$ Biol Chem. 1990;265(8):4570-4577.

139. Bagby GJ, Pekal PH. Lipoprotein lipase in trauma and sepsis. In Lipoprotein lipase. In: Borensztajn editor. USA: Chicago, Evener Publishers Inc; 1987;10:247-274.

140. James RW, Brulhart-Meynet MC, Lehmann T, et al. Lipoprotein distribution and composition in obesity: their association with central adiposity. Int J Obes Relat Metab Disord. 1997;21(12):1115-1120.

141. Björntorp P. Heart and soul: stress and the metabolic syndrome. Scand Cardiovasc J. 2001;35(3):172-177.

142. Sabugal R, Robert MQ, Julve J, et al. Decrease in the expression of hepatic lipase activity following partial hepatectomy. Biochim Biophys Acta. 1996;1302(3):193-198.

143. Rodríguez-Sureda V, López-Tejero MD, Llobera M, et al. Social stress profoundly affects lipid metabolism: over-expression of SRBI in liver and changes in lipids and lipases in plasma and tissues of stressed mice. Atherosclerosis. 2007;195:57-65.

144. Verhoeven A, Carling JD, Jansen H. Hepatic lipase gene is transcribed in rat adrenals into a truncated mRNA. J Lipid Res. 1994;35(6):966-975.

145. Reynolds RM, Walker BR, Syddall HE, et al. Altered control of cortisol secretion in adult men with low birth weight and cardiovascular risk factors. J Clin Endocrinol Metab. 2001;86(1):245-250.

146. Rask E, Olsson T, Söderberg S, et al. Tissue-specific dysregulation of cortisol metabolism in human obesity. $J$ Clin Endocrinol Metab.2001;86(3):1418-1421.

147. Andrew RD, Phillips I, Walker BR. Obesity and gender influence cortisol secretion and metabolism in man. J Clin Endocrinol Metab. 1998;83(5):1806-1809.

148. Galan X, Llobera M, Ramírez I. Lipoprotein lipase and hepatic lipase in Wistar and Sprague-Dawley rat tissues. Differences in the effects of gender and fasting. Lipids. 1994;29(5):333-336. 